\title{
Ontology Learning Design toward Supporting Designer
}

\author{
Majdah Alshehri \\ Information Technology Department \\ College of computer and Information Sciences, \\ King Saud University, Saudi Arabia
}

\author{
Azeddin Chikh \\ Information System Department \\ College of computer and Information Sciences, \\ King Saud University, Saudi Arabia
}

\begin{abstract}
In a Learning Design, describing the Learning Design in a consistent and transferable way is significant. However, there are several learning design representations that define Learning Design. IMS-LD is a specification that facilitates representation of leaning design and modeling Learning Design interpretability. Leaning Design is user-intensive, the lack of shared understanding leads to poor communication; Ontologies in this context, aim at solving the former problem. Ontologies facilitate the communication and knowledge sharing by providing a unify framework for parties with different viewpoints. Since the learning design varies from one designer to another, this work proposes a Leaning Design Ontology tool (LDO) that offers possibilities for organizing and visualizing more resource to grant better understanding for concepts and elements of IMS-LD to support designers. In the proposed tool, the semantic ontology concept is provided by defining a description of each concept; and knowledge base is provided by providing resource description.
\end{abstract}

\section{Keywords}

Learning Design, Ontology, IMS-LD Specification, E-learning, Interpretability, Knowledge Base Management.

\section{INTRODUCTION}

Learning Design is "description of a method: enabling learners to attain certain learning objectives, by performing certain learning activities, in a certain order, in the context of a certain learning environment; based on the pedagogical" [13]. In e-learning domain, the central idea behind learning design represents new possibilities for increasing the quality and variety of teaching/learning within an e-learning context. According to Olivier [16], "The term learning design is commonly used today to describe the representation of a learning process and its outcomes in ways that might enable it to be replicated and reused". IMS-LD Specification is the useful solution to describe 'learning design' in a consistent and transferable way that will allow easy re-use.

IMS-LD is a metadata standard. The majority of the metadata standards are just focused on determining the vocabulary to represent the different aspects of the learning process, while the meaning of the metadata elements is usually described in natural language. Although this description is easy to understand for the learning participants, it is not appropriate for software programs designed to process the metadata. To solve this issue, ontologies could be used to describe formally and explicitly the structure and meaning of the metadata elements; that is, an ontology would semantically describe the metadata concepts [9].

The use of ontologies and the semantic web for e-learning is well described in [17]. This is further expanded by Aroya et al [4], who identified the need to capitalize on the use of (1) semantic conceptualization and ontologies, (2) common standardized communication syntax, and (3) large-scale service-based integration of educational content and functionality provision and usage. This paper aims to serve these goals and add value for elearning by using IMS-LD. Developing ontology based on IMSLD has been proposed in [2], this research was on how ontologies can be used to model, validate and execute IMS Learning Design. However, none of the previous studies deal with the intention of "growing context" around the use of learning resources by using IMS-LD.

This work presents LDO tool which support practitioners of IMSLD ontology to share and search for learning resources, based around the pedagogical context for the use of each resource.

This paper is structured as follows: In section 2, overview of Learning Design models is discussed. Describes the proposed leaning design ontology and its architecture is in section 3 . The implementation of proposed LDO tool prototype is examined in section 4.

\section{OVERVIEW LEANING DESIGN MODELS}

\subsection{Overview of Learning Design}

The expression "learning design" is gaining popularity in the elearning literature as a concept for supporting academics to models and shares teaching practice; it is defined as the description of the teaching-learning process that takes place in a unit of learning (e.g. a course, a lesson or any other designed learning event).

By looking inside the unit of learning, Oliver and Tattersall [15] proposed that learning design consists of six elements, as follows: title, learning objectives, prerequisites, components, method, and metadata (see Fig.1).

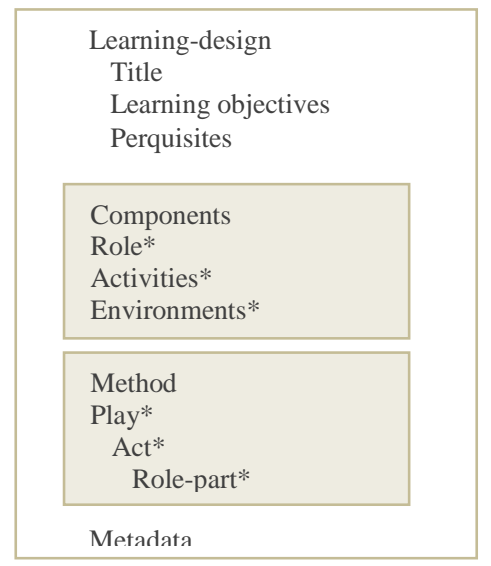

Fig 1: Elements of the learning design 
The previous sign $(*)$ indicates there may be many of these. Components and Method elements are the two main and largest structures in learning design.

The Components defined as core element of the learning design language and include three components, originally identified as the main elements, they are: Roles, Activities, Environment. Roles are the persons who are referred to as actors, according to Britain [9] there are two kinds of Roles used to represent people: learner or staff. Specific individuals are not a generalisable component, but Roles are, so the Role is specified in the design rather than a person; Activities occur on both individual and social levels linked at the same time, these can be of two types, either learning activities or support activities; and Environment is that which holds reference to the recourse and service used by the activities, The Environment element contains two basic types: (1) Learning Objects which would typically be a URL to external content, tools or tests with optional metadata, and (2) Services that refers to a service provided within the environment that is available at runtime but cannot be specified at design-time (e.g. .discussion forums, or chat rooms, etc)

The Method drives the whole process when learning design is being run; it holds the workflow or "learning follow" for the learning design and contains three main nested elements: Play, Act, and Role-parts.

\subsection{IMS-LD Specification}

Learning design representation models have been suggested in several studied. [11], [14].suggested there must be a guidance and advice in an efficient and effective manner to provide the teachers with support in creating innovative pedagogy. [11] Encouraged identifying effective learning activity models and building standardized descriptions.

Several of learning design representations have been proposed, for example E2ML, IMS-LD, Learning Activity Management System (LAMS), Learning Design Visual Sequence (LDVS), LDLite and Patterns. Comparing the representations has been provided in [1] as shown in the table 1 .
Table 1. Comparison of six learning design representations: focus, purpose, and artifacts produced.[1]

\begin{tabular}{|c|c|c|}
\hline specification & Focus & Purpose \\
\hline $\mathrm{E}^{2} \mathrm{ML}$ & $\begin{array}{l}\text { Document the outcome } \\
\text { of an instructional } \\
\text { design process. }\end{array}$ & $\begin{array}{l}\text { Enhance } \\
\text { communication } \\
\text { amongst team of } \\
\text { large e-learning } \\
\text { projects. }\end{array}$ \\
\hline IMS-LD & $\begin{array}{l}\text { Document an online } \\
\text { learning experience (a } \\
\text { unit of learning) in a } \\
\text { computer readable way. }\end{array}$ & $\begin{array}{l}\text { Offer technical } \\
\text { interoperability by } \\
\text { supplying a } \\
\text { complete technical } \\
\text { solution. }\end{array}$ \\
\hline LAMS & $\begin{array}{lr}\text { Create } & \text { online } \\
\text { collaborative } & \text { activities } \\
\text { for students. } & \end{array}$ & $\begin{array}{l}\text { Provide a design } \\
\text { and } \\
\text { Implementation } \\
\text { platform for online } \\
\text { collaborative } \\
\text { activities. }\end{array}$ \\
\hline LDVS & $\begin{array}{l}\text { Provide a visual } \\
\text { summary of a learning } \\
\text { design from the teacher } \\
\text { perspective. }\end{array}$ & $\begin{array}{l}\text { Document learning } \\
\text { designs to } \\
\text { encourage } \\
\text { sharing and reuse } \\
\text { of the pedagogical } \\
\text { ideas. }\end{array}$ \\
\hline LDLite & $\begin{array}{l}\text { Help teachers design } \\
\text { and integrate blended } \\
\text { (face-to-face and } \\
\text { online) activities. }\end{array}$ & $\begin{array}{l}\text { Tool for teachers } \\
\text { to design and } \\
\text { document online } \\
\text { and off-line } \\
\text { learning activities. }\end{array}$ \\
\hline Patterns & $\begin{array}{l}\text { Present solutions to } \\
\text { reoccurring design } \\
\text { problems but not } \\
\text { provide a complete } \\
\text { prepackaged solution. }\end{array}$ & $\begin{array}{l}\text { To guide not } \\
\text { prescribe; to teach; } \\
\text { to offer "rules of } \\
\text { thumb". }\end{array}$ \\
\hline
\end{tabular}

It can be seen that IMS Learning Design is the only interoperability specification that means it enables users to implement learning activities for multiple users while maintaining the flexibility to implement a wide range of pedagogical structures. However, IMS-LD moves beyond designing for lone-learners reading from screens. Its guides staff and educational developers to reflect on learning activities and the achievement of learning objectives. It recognizes that learning can happen without learning objects, that learning is different from content consumption and that learning comes from being active. It recognizes, too, that learning happens when learners cooperate to solve problems in social and work situations. 
According to Britain in [6], the central ideas behind learning design represent new possibilities for increasing the quality and variety of teaching and learning within an e-learning context: (1) The first general idea behind learning design is that people learn better when actively involved in doing something (i.e. are engaged in a learning activity). (2) The second idea is that learning activities may be sequenced or otherwise structured carefully and deliberately in a learning workflow to promote more effective learning. (3) The third idea is that it would be useful to be able to record 'learning designs' for sharing and re-use in the future.

This work emphasize on sharing and re-using Learning Designs idea. IMS- LD Specification is used to describe Learning Design in a consistent and transferable way.

\subsection{Overview of ontology applying to Learning Design}

Considerable amount of the researches on knowledge-based and intelligent systems have moved towards concepts and ontologies [3][8][12][18] and focuses on knowledge sharing and reusability [7][10]. In general, ontology is used to define the basic terms and relations in the domain. It also provides axioms as rules and constraints for manipulating and managing the terms and their relations within this common domain vocabulary. Ontologies allow the definition of an infrastructure for integrating intelligent systems at the knowledge level, independent of particular implementations, thus enabling knowledge sharing [5]. Ontologies can be used as the basis for development of libraries of shareable and reusable knowledge modules. This present work focused on providing different work for achievement support that available for designer.

\section{ONTOLOGY BASED LEARNING DESIGN SUPPORT}

Facilitate the semantic description of IMS-LD elements is the core of this work. According to that, this work proposed in LDO (Learning Design Ontology) tool that can apply semantic description to support designers who use IMS-LD specification and providing knowledge sharing that demonstrates more support for them. In general, many of the researchers announced that there is still much work to be done in tool support-today. This work offers possibilities for organizing and visualizing resource knowledge for support designers by providing LDO tool.

\subsection{Architecture of the proposed tool}

It can be seen as shown in figure 2 that the proposed system is primarily consisting of two main processes: user interface among the system components, and system itself with its external environments (i.e. resources).

The conceptual design of the proposed tool is providing a concise and visually map of the system components and their relationship. In addition, this design allows for information to be communicated effectively by organizing them in a fashion that can be effectively understood by the intended audience

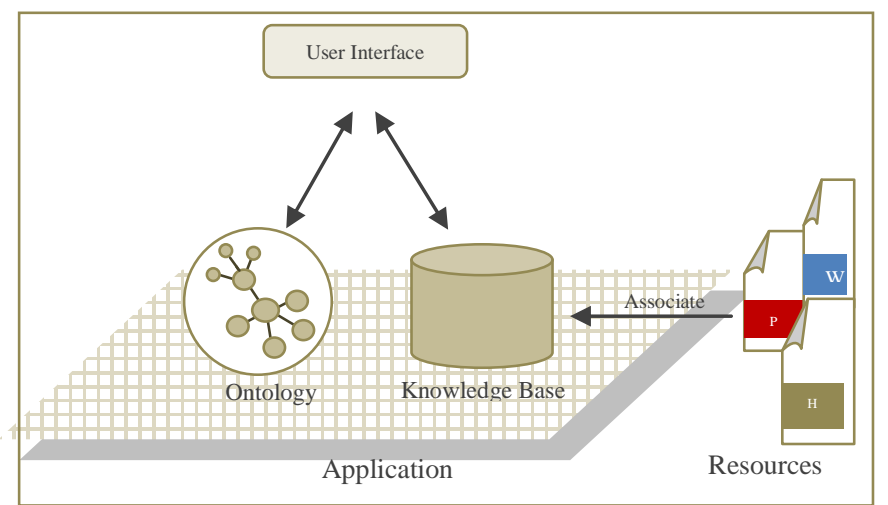

Fig 2: Learning Design Ontology Tool Architecture

The proposed system consists of the following components: User interface, there are two types of graphical interface are considered of this work: Designer interface and Expert interface. Learning Design ontology is describing the concepts that exist in IMS-LD specification and clarify the relations between these concepts. Knowledge base is source of knowledge about a particular domain that holds information, gives details and defines rules. External resources refer to any electronic item on the web that can be used. It could be text, images, videos, music, games and other information typically located on the World Wide Web. And Application, this paper research, states the application is providing tools with the purpose of supporting or improving the software user's work; the application is a program designed to perform a specific function directly for the user or, in some cases, for another application program. It gives infrastructure for core components of this LDO tool system (i.e. ontology and $\mathrm{KB}$ ).

\subsection{Workflow of the proposed tool}

In general, a workflow is a depiction of a sequence of operations, declared as work of a person and seen as any abstraction of real work. In this work, workflow is an activity enabled by a systematic organization, and defined roles. Therefore, the process can be ranged between two primary users; designer and expert.

Designer of learning design is more than just putting information in front of the learners; he/she has clear goals \& gets learners focused on the right things. In order to give better support for designer; this work allows designer to meet one level of activity within two process, browse and retrieve. Meanwhile, Expert has two level of activity within six processes as following: assign to, update, delete, add, retrieve, and search.

Assign to can be assign new knowledge to concept and vice versa; update regarding both concept description and knowledge base information; delete have two level: delete the relation between concept and knowledge base, or delete concept and knowledge base themselves; add refer to both concept and knowledge base; retrieve and browse like the same on the designer process. 


\section{IMPLEMENTATION OF LEARNING DESIGN ONTOLOGY TOOL}

The LDO tool has been implemented to validate the proposed work. It offers Proof-of-Principle prototype type that used to test some aspect of the intended design for learning design ontology support. The aim of this work is to enable proactive and reactive providing information sources to best support designers and define more richly information.

The prototype interface provides four different views: concept gate, knowledge gate, tree view and semantic conceptual graph. This will allow designers to get access and doing the operation. Concept gate implies theoretical concepts that represents IMS-LD domain; while knowledge gate is dynamic information of the resource; the tree view and semantic conceptual graph are formulation in-depth explanation, they are more advanced view regarding concept representation (see figures 3-6).

In this work, semantic description of the IMS-LD element is provided in double sides; on the one hand is ontology by defining description of each concept. The concept can be well semantic by shows concept description in concept details area. The aim of concept's description is organizing and recorded information about each concept and remove ambiguity. Meanwhile the description of concept provided, the knowledge related to the concept are provided too and shown in knowledge details. This knowledge is URL formats that gives to explain each concept practically and give an example. The other hand is knowledge base by provide some of LOM elements. LOM metadata has been chosen to provide better resources description. LOM metadata element used to provide full support to the designers by provided description of the knowledge that provided best example to each concept.

The LOM employed in this proposed tool essentially based on educational category that represents group of educational and pedagogic characteristics of the learning object. In addition, other categories are provided, these categories distinguish as following: (1) General category, resources title is name given to this learning knowledge; and resource identifier is globally unique label that identifies this learning object. (2) Technical category, format is technical data type(s) of (all the components of) this knowledge; Size represent size of the digital learning object in bytes; and location is used to access this learning object. (3) Educational category, Learning Resource Type is specific kind of learning object; Context is the principal environment within which the learning and use of this learning object is intended to take place; Interactivity Type is predominant mode of learning supported by this learning object; Difficulty shows how hard it is to work with or through this learning object for the typical intended target audience; Language is the human language used by the typical intended user of this learning object; Semantic Density presents degree of conciseness of a learning object, the semantic density of a learning object may be estimated in terms of its size, span; Typical Learning Time is approximate or typical time it takes to work with or through this learning object for the typical intended target audience; Interactivity Level is degree of interactivity characterizing this learning object, Interactivity in this context refers to the degree to which the learner can influence the aspect or behavior of the learning object ; Typical Age Range shows Age of the typical intended user, this data element shall refer to developmental age, if that would be different from chronological age; Description is comments on how this learning object is to be used.

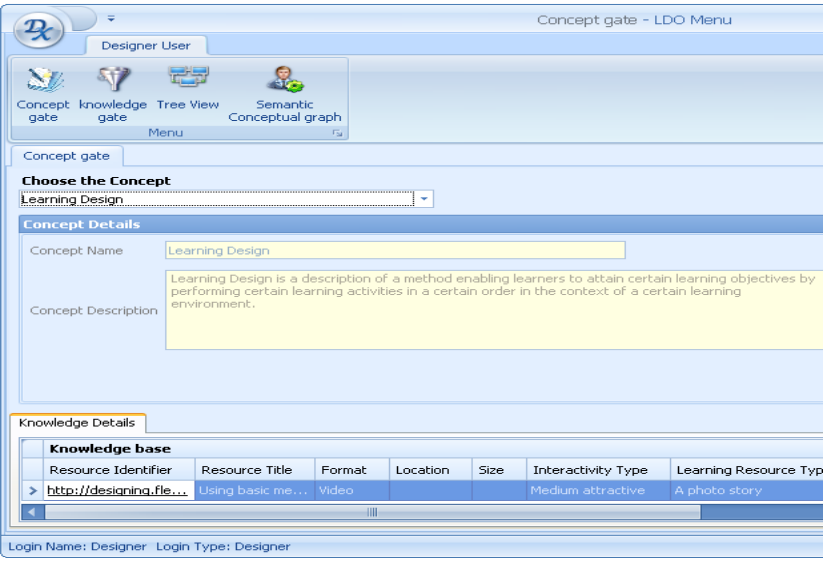

Fig 3: A screenshot showing LDO tool concept gate

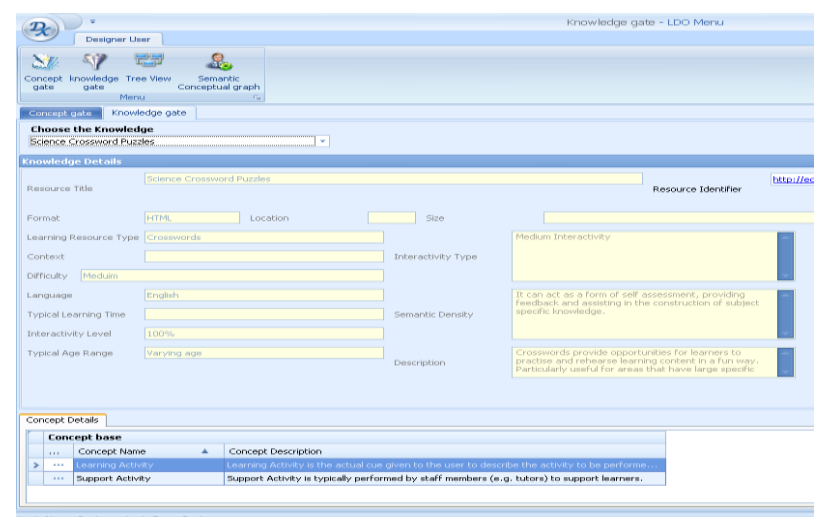

Fig 4: A screenshot showing LDO tool knowledge gate

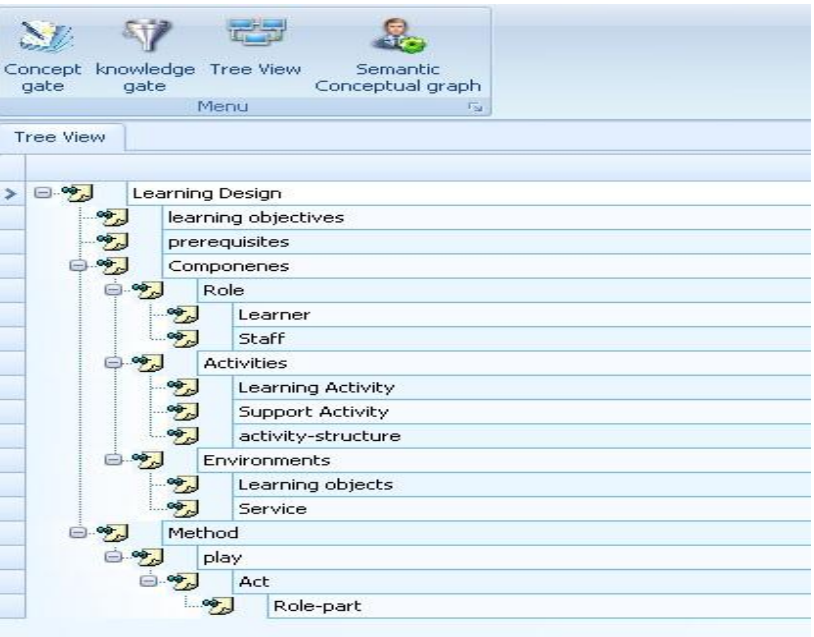

Fig 5: A screenshot showing LDO tool Tree view 


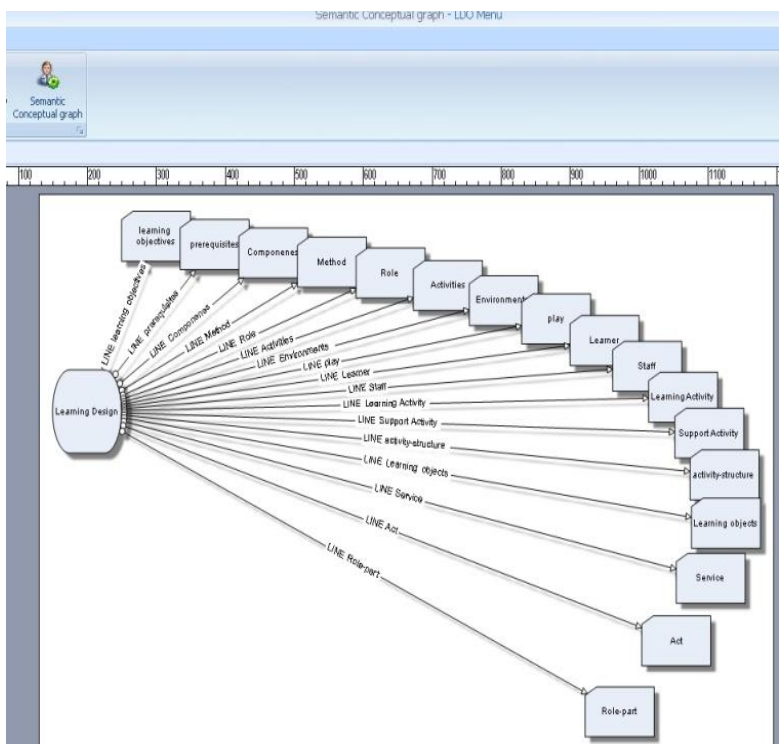

Fig 6: A screenshot showing LDO tool Semantic conceptual graph

\section{CONCLUSION}

In this research, Learning Design Ontology tool is proposed to produce semantic learning design ontology to support designer within IMS-LD Specification. the motivation of this work are on one hand support to achieve learning design in distinctive level of abstraction. IMS-LD is offering constructs generic to different pedagogical approaches. By using ontology based IMS-LD, designers are able to talk in terms of pedagogy rather than technology, thereby making pedagogical choices explicit and subject to review, inspection, critique and comparison. the other hand, supports use rise reusing. IMS LD separates the approach to learning from the learning objects and services used. Therefore, opportunities for re-use are raised. the contribution of this paper are proppe model and develop a LDO tools that validates the proposed model. Moreover, LDO Tool represents a semantic ontology and helping designer when design unit of learning. This tool allows create knowledge base as well as assigned knowledge base to each concept of ontology

Although, learning design ontology is in infancy stage, this research overcomes the obstacles and success to return satisfied result. The summary of this research findings is sum up into three points: Conceptual design system demonstrated that is "good enough" architecture for extended to interact within semantic metadata. This might be attributed to the application layers; create a new and more precise binding for learning design. Although structure concepts are neither perfect nor complete, they have added potential contextual dimensions to the generated semantic ontology; and provide ontology that enriched way of learning resources as well as provide a flexible mechanism to share the meaning of a learning design domain.

The future work can be defined on two directions: (1) Tool enhancement, even if the prototype tool presented in this research has achieved its intended goals, there are many potential extensions that can enhance the tool's performance and output. (2) Integrated with other domains that gave complementary way (i.e. pattern language learning design).

\section{REFERENCES}

[1] Agostinho, S. (2008). Learning Design Representations to Document, Model, and Share Teaching Practice, In Lockyer, L., Bennet, S., Agostinho, S., Harper, B. (Eds.). Handbook of Research on Learning Design and Learning Objects: Issues, Applications and Technologies, pp. 1-19, IDEA group.

[2] Amorim, R., Lama, M., Sánchez, E., Riera, A., \& Vila, X. A:. $A$ Learning Design Ontology based on the IMS Specification. Educational Technology \& Society, 9 (1), 38-57 (2006)

[3] Aroyo, L., \& Dicheva, D.: Courseware Authoring Tasks Ontology. In Kinshuk, R. Lewis, K. Akahori, R. Kemp, T. Okamoto, L. Henderson \& C.-H. Lee (Eds.) Proceedings of the International Conference on Computers in Education, Los Alamitos, CA: IEEE Computer Society, 1319-1321 (2002)

[4] Aroyo, L, \& Dicheva, D.: The new challenges for e-learning: the educational semantic web. Educational Technology \& Society, 7(4), 59-69 (2004)

[5] Breuker, J., \& Bredeweg, B.: Ontological Modeling for Designing Educational Systems, Paper presented at the Workshop on Ontologies for IES at AIED'99, 19-23 July, Le Mans, France (1999)

[6] Britain, S.: A Review of learning design: Concept, specifications and tools: A report for the JISC e-Learning Pedagogy Programme. Retrieved 1 August, 2007, from http://www.jisc.ac.uk/uploaded_documents/ACF1ABB.doc (2004)

[7] Chen, W., Hayashi, Y., Kin, L., Ikeda, M., \& Mizoguchi, R.: Ontological Issues in an Intelligent Authoring Tool. In Chan T-W., Collins A. \& Lin J. (Eds.) Proceedings of the ICCE'98 Conference, Norfolk, VA: AACE, 41-50 (1998)

[8] Devedzic, V.: The Semantic Web - Implications for Teaching and Learning, In C. H. Lee, S. Lajoie, R. Mizoguchi, Y D. Yoo \& B. du Boulay (Eds.) Enhancement of Quality Learning Through Information \& Communication Technology (ICT), Proceedings of ICCE/SchoolNet 2001 Conference, Korea: Incheon National University of Education, 29-30 (2001)

[9] Gómez-Pérez, A., Fernández-López, M., Corcho, O.: Ontological Engineering, Springer Verlag, (2003)

[10] Ikeda, M., Seta, K., \& Mizoguchi, R: Task Ontology Makes It Easier To Use Authoring Tools. Paper presented at the Fifteenth International Joint Conference on Artificial Intelligence (IJCAI'97), 23-29 August, Nagoya, Japan (1997)

[11] Laurillard, D. (2002). Design tools for e-learning. In Proceedings of the 19th Annual Conference of the Australasian Society for Computers in Tertiary Education, Auckland, New Zealand, UNITEC Institute of Technology on Winds of change in the sea of learning.

[12] Mizoguchi, R., \& Bourdeau, J.: Using Ontological Engineering to Overcome Common AI-ED Problems. International Journal of Artificial Intelligence in Education, 11 (2), 107-121 (2000)

[13] Odette A:. Instructional management system- learning design. parise 2 university, France (2005)

[14] Oliver, R., \& Littlejohn, A. (2006). Discovering and describing accessible and reusable practitioner- pocused learning. in Proceedings of Theme 1 of the JISC Online Conference for Innovating e-Learning 2006 (pp. 30- 33). Retrieved March 22, 2008, from http://www. jisc.ac.uk/elp_conference06.html 
[15] Olivier, B.\&Tattersall, C. (2005). The Learning Design Specification In: Koper, R.\&Tattersall, C., Learning Design: A Handbook on Modelling and Delivering Networked Education and Training (pp. 21-40). Berlin-Heidelberg: Springer Verlag.(2005)

[16] Oliver, R.: Learning Designs for ICT-based Learning Settings. $\quad$ Retrieved $15.02 .07, \quad$ from http://www.ascilite.org.au/index.php/Newsletter:_July_2006 (2006)
[17] Sampson, D. G, Lytras, M. D, Wagner, G \& Diaz, P.: Ontologies and the Semantic Web for E-learning. Educational Technology \& Society, 7(4), 26-28. (2004)

[18] Vasilakos, A., Devedzic, V., Kinshuk, \& Pedrycz, W. (in press). CI in Web-based Education: A Tutorial. Journal of Interactive Research on Learning. 